\title{
REAVI
}

\section{A PERCEPÇÃO DOS GESTORES DA UNIDADE DE CONTROLE INTERNO EM UM ÓRGÃO PÚBLICO DO RIO GRANDE DO NORTE}

\author{
THE PERCEPTION OF THE MANAGERS OF THE INTERNAL \\ CONTROL UNIT IN A PUBLIC AGENCY OF RIO GRANDE DO NORTE
}

\author{
Sérgio Luiz Pedrosa Silva* \\ Wênyka Preston L. Batista da Costa** \\ Jandeson Dantas da Silva*** \\ Ítalo Carlos Soares do Nascimento**** \\ Rafael Ramon Fonseca Rodrigues*****
}

\section{RESUMO}

O objetivo desse estudo foi analisar a percepção dos gestores de um órgão público no RN no tocante ao conhecimento e procedimentos da Unidade de Controle Interno (UCI). A pesquisa classifica-se como quantitativa, possui caráter descritivo, tendo como procedimento técnico o levantamento do tipo survey. Os dados foram coletados através de questionário, estruturado com 15 perguntas diretas, atingindo 78 gestores. Os resultados evidenciaram que $80 \%$ dos gestores destacaram desconhecer as legislações internas da UCI; 75\% visualizam a UCI como órgão de controle a posteriori; e $83 \%$ apontaram a falta de feedback sobre os processos. Além disso, constataram-se problemas relacionados ao modelo COSO, especialmente quanto ao ambiente de controle, informação e comunicação, e sobre as atividades de controle. Evidenciou-se ainda a necessidade de promover melhorias, principalmente no tocante a gestão da UCI. A pesquisa apresenta contribuições ao destacar a necessidade desse órgão público direcionar estratégias gerenciais para resolver os problemas apresentados em sua gestão, tendo em vista que os problemas evidenciados podem servir de direcionador para promover melhorias em outras UCI's, as quais fazem parte das estruturas dos órgãos públicos do Brasil.

Palavras-Chave: Unidade de Controle Interno (UCI). Tribunal de Contas Estadual. COSO.

\begin{abstract}
The objective of this study was to analyze the perception of the managers of a public agency in $\mathrm{RN}$ regarding the knowledge and procedures of the Internal Control Unit (UCI). The research is classified as quantitative, has a descriptive character, having as a technical procedure the survey type survey. Data were collected through a questionnaire, structured with 15 direct questions, reaching 78 managers. The results showed that $80 \%$ of the managers highlighted that they were unaware of the internal laws of the UCI; $75 \%$ view the ICU as a post-control body; and $83 \%$ pointed out the lack of feedback on the processes. In addition, problems related to the COSO model were found, especially regarding the control, information and communication environment, and control activities. The need to promote improvements was also highlighted, especially with regard to the management of the UCI. The research presents contributions by highlighting the need for this public agency to direct managerial strategies to solve the problems
\end{abstract}

\footnotetext{
* UERN - Universidade do Estado do Rio Grande do Norte/RN. E-mail: sergiopedrosa@uern.br

*** UERN - Universidade do Estado do Rio Grande do Norte/RN. E-mail: wenykapreston@ hotmail.com

*** UERN - Universidade do Estado do Rio Grande do Norte/RN. E-mail: jandeson.dantas@gmail.com

***** UFC - Universidade Federal do Ceará/CE. E-mail: italocarlos25@ gmail.com

****** UERN - Universidade do Estado do Rio Grande do Norte/RN. E-mail: rafaelrcontador@gmail.com Revista Eletrônica do Alto Vale do Itajaí - REAVI, v.09, n 14, p. 016-039, ago. 2020
}

ISSN: 2316-4190, DOI 10.5965/2316419009142020016 
presented in its management, considering that the evidenced problems can serve as a driver to promote improvements in other UCI's, which are part of the structures of public agencies of Brazil.

Keywords: Internal Control Unit (UCI). State Court of Accounts. COSO.

Data de submissão: 22 de maio de 2020.

Data de aprovação: 20 de julho de 2020.

Disponibilidade: http://www.revistas.udesc.br/index.php/reavi/index

\section{INTRODUÇÃO}

Hoje, com os avanços da tecnologia da informação, cada vez mais se buscam alternativas que possam trazer melhorias aos resultados das ações administrativas praticadas nas instituições que forneçam elementos pertinentes para subsidiar os administradores públicos nas suas tomadas de decisão.

Dessa forma, para que esses aspectos se tornem precisos e os gestores consigam ter o entendimento do que ocorre nas suas instituições devem dispor de um sistema de gestão interna eficaz. Reflete-se que um conjunto de ações devem ser tomadas para a sua formação, as quais permitem o planejamento gerencial das atividades de uma organização (órgão institucional), contemplando as compras, as vendas, a avaliação das ações, os objetivos estratégicos e operacionais, como também impedindo erros e fraudes com a finalidade de obter dados contábeis confiáveis (MORAIS; TEIXEIRA, 2016; PETER; MACHADO, 2009).

Nessa conjuntura, observam-se diferentes descrições sobre a conceituação do controle interno, dentro dessa variedade, esta pesquisa pretende selecionar a conceituação pertinente para o uso da administração na atualidade, pois o seu foco está prioritariamente em instituições públicas. O controle interno na gestão pública é primordial para o bom funcionamento da máquina administrativa, pois, promove a efetividade das operações patrimoniais na administração (CREPALDI, BIANCHI, 2015).

Com isso, observa-se que, tanto as entidades públicas como empresariais, necessitam de uma sistemática que favoreça o alcance dos objetivos almejados pela instituição. A auditoria interna procura contribuir para evitar erros e fraudes que possam acontecer na operacionalização das transações, Holanda (2019) ressalta, ser indispensável que qualquer entidade, independente de tamanho e característica, que desempenhe, onde as fontes de receitas sejam os recursos públicos ser essencial um sistema de controle para promoção de uma gestão administrativa que atue permeada pelos princípios da administração pública.

Desse modo, com o objetivo de cumprir a sua função, controlar e colaborar para tornar eficiente a gestão, assim, foram criadas estruturas que delimitam e regulam esse funcionamento, as Unidades de Controle Interno (UCI). Essas unidades são capazes de manter atualizadas as orientações e instruções normativas, resoluções e manuais. Destaca-se como um dos princípios básicos do controle interno a segregação de função, configurando-se como fundamental na gestão pública, já que a sua aplicação e necessidade aparece em todas as etapas da execução da despesa pública (MARSCHNER; SOMMER; WELTER, 2018; TANAKA, 2012).

Associado ao controle interno, a Governança Corporativa coopera para instruir e regular como a gestão pública deve desenvolver suas atividades, tendo como objetivo amenizar os 


\section{REAVI}

conflitos de agência, que se evidenciam das divergências de interesses entre os agentes, envolvendo problemas de informações assimétricas, que se constata pelos stakeholders terem informações incompletas de uma mesma organização, levando as partes interessadas a tomarem decisões diferentes. Nas organizações públicas, conforme Elias, Daumal e Bernadini (2013) relatam que, esses conflitos são marcados por questões políticas e das relações de trabalho, compreendendo que os órgãos públicos, como pluralidades de pensamentos e ideologias distintas, constitui espaço propício para conflitos de variadas formas (COOPER; MORGAN, 2008).

Destaca-se que este estudo se desenvolveu sobre a UCI de uma fundação pública do Rio Grande do Norte (RN), na cidade de Mossoró, que possui uma população flutuante de 250 mil pessoas, destacando-se como a $2^{\mathrm{a}}$ cidade do RN, em que as suas principais culturas são, petróleo, sal marinho e fruticultura irrigada, com destaque para o sal marinho, com a maior produção nacional, assim, como o maior produtor de melão do país, com exportações para vários países, pelo porto de Natal-RN. A instituição onde se realizou o estudo atua na área educacional do ensino superior, em que possui12 mil alunos, entre graduação e pós-graduação, localizando-se sua Unidade Central, em Mossoró-RN (SILVA, 2019).

Diante disso, emerge o questionamento deste estudo: qual a percepção dos gestores de um órgão público no RN no tocante ao conhecimento e procedimentos da Unidade de Controle Interno (UCI)? Portanto, seu objetivo é de analisar a percepção dos gestores de um órgão público no RN no tocante ao conhecimento e procedimentos da UCI.

Diante do exposto, a pesquisa justifica-se por apresentar uma temática atual, relevante e pouco explorada em âmbito nacional, permitindo o aprofundamento e ampliação dos debates sobre o tema e servindo de orientações para futuras pesquisas, como também para outras instituições públicas. Além disso, diante da relevância deste órgão, contribui no entendimento a respeito da UCI de uma fundação do RN como possível redutora nos conflitos de agência, por promover o controle da legalidade dos processos no âmbito público.

$\mathrm{O}$ estudo encontra-se estruturado em cinco seções, incluindo esta introdução. Na sequência, apresenta-se o referencial teórico, que embasa sobre as legislações federais e estaduais sobre Unidades de Controle Interno (UCI), a terceira seção apresenta a metodologia, que explica os procedimentos metodológicos para realizar a pesquisa empírica, a quarta seção expõe os resultados do estudo, a última seção apresenta as considerações finais e as referências utilizadas.

\section{REFERENCIAL TEÓRICO}

O referencial teórico expõe a fundamentação teórica responsável para auxiliar o entendimento do objeto dessa pesquisa. Assim, buscou os principais referenciais no estado da arte para contribuir na formulação do questionário, que se utilizou na coleta de dados e na conclusão, promovendo o suporte necessário para se relacionar o teórico com o empírico.

\subsection{INTRODUÇÃO AO CONTROLE INTERNO}

O termo controle, apesar de designação no latim rotulum - relação dos contribuintes, e possuir vários significados, de acordo com Castro (2010), esse termo sempre foi ligado às finanças, em que no francês significa contrôler, que significa inspecionar e examinar. Do ponto 
de vista histórico, a primeira notícia que se tem sobre o controle de gastos públicos deu-se na Grécia Antiga e funcionava com fiscais eleitos pela Assembleia Popular.

Com a solidificação do Estado Democrático de forma mais aberta e transparente, todos os bens e arrecadação do Estado passaram a ser patrimônio da coletividade, para usufruto das suas necessidades, asseguradas pela constituição. Assim, chega-se ao controle como relevante ferramenta na administração governamental no processo da despesa pública, pois, esse processo está permeado pelos aspectos da legalidade, que norteiam a administração pública, com isso, passou-se a existir previsão de um controle nos atos da gestão pública (NASCIMENTO et al., 2015).

O controle interno de um órgão público é um conjunto de ações responsável por regular, observar e corrigir o trâmite dos processos financeiros na administração pública. Esta concepção assegura que a administração possa realizar seus atos atendendo aos princípios da administração pública, com caráter preventivo e permanente (MARSCHNER; SOMMER; WELTER, 2018). Assim, este conceito deve promover o resguardo do patrimônio público, controlando o planejamento público, para verificar possíveis desvios do que foi planejado e propor medidas corretivas, para se restabelecer o que fora planejado pelos órgãos competentes, devendo desempenhar suas funções básicas, seguindo os princípios impostos pela legislação para o andamento e controle processual correto dos setores envolvidos na gestão pública (CARDIN et al., 2015; LOPES et al., 2015).

Na gestão dos entes públicos, os sistemas de controle interno são vitais para a prestação de um serviço público com qualidade pela administração governamental, em que, os processos requerem o acompanhamento e adaptação as novas tecnologias, como a digitalização dos processos e assinaturas eletrônicas. Os sistemas de controle Externo estão imbuídos na legalidade e no monitoramento subsequente, enquanto as Unidades de Controle Interno atuam, principalmente, de forma antecedente, o monitoramento tem o objetivo de evitar que os processos sejam aprovados com vícios, no tocante aos aspectos da legalidade do serviço público (SOUSA; SOUTO; NICOLAU, 2017; CARDIN et al., 2015).

Dentre as funções administrativas do controle interno, está a prestação de informações permanentes aos órgãos de controle superior sobre toda e qualquer área relacionada com o controle. No caso do Estado do RN, os órgãos de reporte é o Tribunal de Contas do Estado (TCE-RN) e a Controladoria do RN (CONTROL). Destaca-se ainda, como função, resguardar os interesses institucionais contra práticas ilegais, através da fiscalização e recomendações de melhorias e, nesse contexto, se apresentam as Unidades de Controle Interno (UCI), que desempenham esse papel como órgão subordinado ao TCE e a CONTROL (HOLANDA, 2019; TANAKA, 2015; DC 28.684/2018).

Seguindo esse raciocínio, atualmente o controle atua preventivamente ou de forma corretiva, com a incumbência de resguardar o patrimônio público, propiciando o controle das causas para evitar erros com probabilidade de ocorrência (PETER; MACHADO, 2009). Neste contexto, sua função exercida no âmbito do poder público, por meio da Controladoria, tem a finalidade de controlar os atos da gestão em todos os seus aspectos.

\subsection{O CONTROLE INTERNO E O MODELO COSO}

Em razão da proliferação de escândalos financeiros que surgiram nas últimas décadas, com o intuito de resguardar os investidores, principalmente nos EUA e países desenvolvimentos, em que o mercado de capitais é prática recorrente, desencadeou-se, por meio de instituições nos

Revista Eletrônica do Alto Vale do Itajaí - REAVI, v.09, nº 14, p. 016-039, ago. 2020

ISSN: 2316-4190, DOI 10.5965/2316419009142020016 


\section{REAVI}

EUA, modelos de controle interno. Para conter as fraudes nas instituições, editaram o COSO Report, destacando-se desde então, como relevante instrumento no monitoramento de risco nas organizações e detecção de fraudes através do controle interno. Destaque-se que esse modelo, criado em 1985, foi evolução dos modelos existentes, como Repport (1994), CoCo (1997), Turnbull Report (1999), tendo já passado por várias atualizações desde sua criação (BRANDÃO, 2012; FARIAS; DE LUCA; MACHADO, 2009).

O Committe of Sponsoring Organizations (COSO), modelo que se estabeleceu como referencial no planejamento e estudos relacionados ao controle interno, por ampla utilização no setor privado, como modelo fundamental para utilização em estruturas integradas, passou a ser utilizado na esfera pública com adaptações (SOARES; RODRIGUES JÚNIOR, 2019; BEUREN; ZONATTO, 2014). Na visão de Gerigk, Clemente e Ribeiro (2014) os gestores públicos necessitam de um suporte eficiente para promoverem as mudanças ocorridas no ambiente organizacional para realizar um serviço de qualidade para a população.

A metodologia COSO, segrega o controle interno em cinco componentes interrelacionados que devem atuar em todas as unidades e atividades, que são: (i) ambiente de controle que promove o ritmo da organização, através de um processo de conscientização das pessoas, sobre a relevância do sistema de controle interno; (ii) avaliação de risco, na busca de identificar os riscos proeminentes, para o atingimento dos objetivos institucionais; (iii) atividades de controle, que promovem os direcionamentos para garantir a atendimento às normas e procedimentos; (iv) informação e comunicação, realiza a gestão das informações; e (v) monitoramento, processo que visa acompanhas a execução das atividades, para averiguar a sua conformidade com as normas e procedimentos de controle (GATTRINGER; MARINHO, 2020; SOARES; RODRIGUES JÚNIOR, 2019).

Em estudo realizado por Gattringer e Marinho (2020) sobre a aplicação do modelo COSO em municípios catarinenses, os autores evidenciaram que, nos referidos municípios, os 5 (cinco) componentes do modelo COSO-2013 atingiram satisfatoriamente os requisitos do sistema COSO para a eficácia do controle interno; revelaram ainda que os componentes, ambiente de controle, e informação/comunicação estão na média para eficácia operacional, apontando necessidade de melhorias; já no componente, ambiente de controle, detectou-se falta de recompensas para os colaboradores, e de uma política de incentivo ao desempenho; no componente informação e comunicação, detectou-se necessidade de aprimoramento da ouvidoria e implantação de diretrizes de controle interno para uma melhor comunicação, e na atividade de controle e monitoramento evidenciaram requisitos satisfatórios para atender os requisitos da metodologia COSO.

Portanto, evidencia-se, através da literatura e de achados empíricos, uma metodologia que pode ser utilizada nos órgãos públicos, uma vez que é um modelo de comprovada efetividade no gerenciamento do controle interno, contribuindo assim, para a asseguração de melhorias no ambiente institucional dos órgãos públicos (GATTRINGER; MARINHO, 2020).

\subsection{O CONTROLE INTERNO NA ADMINISTRAÇÃO PÚBLICA}

A administração pública pode ser compreendida como todo o aparelhamento do Estado, organizado e disponível para prestação de serviços a sociedade, com o objetivo de atender aos anseios da coletividade (PETINGA, 2018; MEIRELLES, 2016). A CF de 1988 estabeleceu definitivamente a organização dos entes públicos de forma democrática e no intuito de atender a todos os brasileiros, baseada em princípios sobre a conformidade das estruturas e da atividade

Revista Eletrônica do Alto Vale do Itajaí - REAVI, v.09, no 14, p. 016-039, ago. 2020

ISSN: 2316-4190, DOI 10.5965/2316419009142020016 
administrativa, está incumbida por seus órgãos de fazer a coisa pública, enredada nos direitos fundamentais, vislumbrando a coletividade (SOUSA; SOUTO; NICOLAU, 2017; TANAKA, 2012).

Para satisfizer a contento essa necessidade democrática, a Administração precisa se mostrar eficiente, estabelecendo estratégias, no exercício de suas atividades, que permitam, na prática, acompanhar os atos dos gestores públicos e a concretização dos objetivos e metas estabelecidos, aperfeiçoando a atividade administrativa (MELO; SANTOS; GIROTTO, 2011).

Assim, é notório que a Administração Pública deve caminhar lado a lado com o controle interno. A administração precisa ser democrática e, consequentemente, eficiente no desempenho de suas atividades, já que tem que atender aos interesses coletivos. A atribuição do controle interno, nesse cenário, torna-se imprescindível, pois atua no aperfeiçoamento do exercício administrativo da gestão, contribuindo para que a eficiência seja não apenas almejada, mas também alcançada (LOPES et al., 2015; TANAKA, 2012).

O controle interno é um sistema amplo e complexo que busca estabelecer procedimentos, métodos, abordagens e critérios que devem cobrir todas as áreas da instituição em vista da prevenção, controle, previsão e correção diante dos diversos problemas operacionais que podem comprometer os objetivos buscados pelos administradores (FARIAS; DE LUCA; MACHADO, 2009).

O controle interno é um órgão permanente e busca garantir o mínimo de segurança para que sejam alcançados os objetivos, resultando na produção de informações confiáveis. Rodrigues e Soares Júnior (2019) definem o processo de controle interno de uma entidade, como aquele que se processa por meio do gerenciamento da gestão pública, por intermédio dos profissionais que atuam no monitoramento das atividades, para que se obtenha a segurança de que as atividades desempenhadas pelo órgão estejam atendendo aos requisitos de procedimentos e normas estabelecidos no âmbito institucional (CARDOSO; ESTRELA, 2018; SOUSA; SOUTO; NICOLAU, 2017).

Destaca-se em estudos acadêmicos, nos quais analisam práticas de auditoria e controle nas instituições públicas, que questões culturais da sociedade atual são refletidas na gestão. Entretanto, constata-se que os gestores públicos precisam atuar dentro do princípio da legalidade, buscando acompanhar as diretrizes de controle interno da instituição. Dessa forma, evidencia-se o Decreto Estadual $n^{\circ} 28.684$, de 2018, as UCI, s em que, devem priorizar o exercício de suas funções em concordância as normas de controle interno, objetivando garantir a segurança, a permanência do controle de recursos e o bom fluxo dos métodos estabelecidos, para promover a utilização dos recursos públicos eficientemente e com transparência (MARSCHNER; SOMMER; WELTER, 2018; NASCIMENTO et al., 2015).

No entendimento de Silva e Mário (2015), operacionalizar os recursos financeiros públicos através da chancela da auditoria interna é relevante para segurança dos gestores e da forma como os recursos públicos forma utilizados, a auditoria interna detecta as possíveis falhas, examinando as atividades desempenhadas pela instituição, exercendo uma função de monitoramento. $\mathrm{O}$ controle interno proporciona aos administradores os meios para instituírem condutas e acompanhar o funcionamento da organização. Na administração pública, a utilização e implantação de um sistema de controle interno, é determinado, segundo as diretrizes da Lei de Responsabilidade Fiscal (LRF) (MARSHCHNER; SOMMER; WELTER, 2018; BEUREN; ZONATTO, 2014).

No que lhe concerne, o controle interno está atrelado as técnicas e práticas seguras para assessorar a gestão da entidade. Assim, sob essa perspectiva, o controle trabalha para verificar as 


\section{REAVI}

atividades executadas pela entidade, relacionadas com comportamento dos agentes públicos. Assim, analisam-se os processos, para se comprovar efetivamente suas conformidades ou não conformidades para entidade (ATTIE, 2011; OLIVEIRA, 2009).

\subsection{O CONTROLE INTERNO - LEGISLAÇÃO FEDERAL E ESTADUAL}

Através do Quadro 1 evidenciam-se as leis pelas quais o controle interno foi evidenciado no âmbito federal. O Decreto-Lei ${ }^{\circ}$ 200/67 tratou sobre a reforma administrativa do Estado, bem como a Lei $n^{\circ} 4.320 / 64$, a qual promoveu o controle da execução da despesa pública dos entes da federação brasileira, onde se estabeleceu seu aspecto jurídico e formal dos controles externo e interno das instituições públicas no país.

Quadro 1 - Principais legislações que regulamentam as atividades de controle interno

\begin{tabular}{|c|c|}
\hline $\begin{array}{c}\text { CONSTITUIÇÃO } \\
\text { FEDERAL 1988 }\end{array}$ & $\begin{array}{r}\text { Art. 70. A fiscalização contábil, financeira, orçamentária, operacional e patrimonial da União } \\
\text { e das entidades da administração direta e indireta, quanto à legalidade, legitimidade, } \\
\text { economicidade, aplicação das subvenções e renúncia de receitas, será exercida pelo } \\
\text { Congresso Nacional, mediante controle externo, e pelo sistema de controle interno de cada } \\
\text { Poder. }\end{array}$ \\
\hline LEI 4.320/64 & $\begin{array}{c}\text { Art. 74. Os Poderes Legislativo, Executivo e Judiciário manterão, de forma integrada, sistema } \\
\text { de controle interno. }\end{array}$ \\
\hline LEI 101/00 & $\begin{array}{c}\text { Art. 59. O Poder Legislativo, diretamente ou com o auxílio dos Tribunais de Contas, e o } 0 \\
\text { sistema de controle interno de cada Poder e do Ministério Público, fiscalizarão o } \\
\text { cumprimento das normas desta Lei Complementar, com ênfase no que se refere. }\end{array}$ \\
\hline
\end{tabular}

Fonte: Elaborado pelos autores, com base em Constituição Federal de 1988, Lei no 4.320/1964, Lei n 101/2000, Resolução CNJ nº 86/2009.

Dessa forma, com a CF de 1988, no art. 70, evidencia-se o controle da execução orçamentária, em que a fiscalização contábil, financeira, orçamentária, operacional e patrimonial dos entes federados e, inclusive a indireta, passou a exercida pelo Congresso Nacional, através do controle externo, e pelo sistema de controle interno de cada Poder, no tocante a observância dos princípios da legalidade, legitimidade e economicidade (MARSCHNER; SOMMER; WELTER, 2018; BRASIL, 1988).

Com a edição da LRF n. ${ }^{\circ}$ 101/2000, passou-se a exigir a implantação de um Sistema de Controle Interno no âmbito público de todos os entes federados, estabelecendo a responsabilidade aos gestores públicos a incumbência de criar e implantar o Controle Interno em todos os órgãos públicos do Brasil. Assim, no Quadro 2, apresentam-se as legislações que foram estabelecidas sobre o sistema de UCI, no âmbito do RN.

Quadro 2 - Legislações Estaduais sobre Sistema de Controle Interno

\begin{tabular}{|c|c|}
\hline $\begin{array}{c}\text { Constituição Estadual do RN } \\
\text { Art. 55 }^{\circ}\end{array}$ & $\begin{array}{c}\text { Promoveu a exigência no âmbito Estadual da implantação do controle interno } \\
\text { nas instâncias, executiva, legislativa e judiciária. }\end{array}$ \\
\hline Lei Complementar $\mathbf{n}^{\mathbf{0}} \mathbf{1 5 0 / 1 9 9 7}$ & Lei que criou e estabeleceu a Controladoria Geral do RN \\
\hline $\begin{array}{c}\text { Lei Complementar } \mathbf{n}^{\mathbf{0}} \mathbf{4 6 4 / 2 0 1 2}, \\
\text { art. 147, 148 e 149 }\end{array}$ & Criou a Lei Orgânica do TCE do RN \\
\hline
\end{tabular}


...continuação.

\begin{tabular}{|c|c|}
\hline $\begin{array}{l}\text { Lei Complementar Estadual } n^{\circ} \\
\qquad 638 / 2018 \text { art. } 3^{\circ}\end{array}$ & $\begin{array}{l}\text { Estabeleceu os meios de controle dos recursos governamentais, dos entes } \\
\text { públicos e privados no RN }\end{array}$ \\
\hline $\begin{array}{l}\text { Decreto Estadual } \mathrm{n}^{\circ} \\
28.684 / 2018,{\text { art. } 33^{\circ}}^{\circ}\end{array}$ & Estabeleceu os procedimentos de regulamentação da LC nº 638/2018 \\
\hline $\begin{array}{l}\text { Instrução Normativa } n^{\circ} 002, \text { de } \\
1 \text { de outubro de } 2018 \text {. }\end{array}$ & $\begin{array}{l}\text { Ordenou sobre as atribuições das UCI, s dos órgãos e entidades do Poder } \\
\text { Executivo, e a outros entes que atuam junto ao setor público. }\end{array}$ \\
\hline
\end{tabular}

Fonte: Elaborado pelos autores, com base nas Legislações do RN.

No Rio Grande do Norte, o controle interno foi disciplinado por meio do art. 55 da Constituição Estadual. Dessa forma, estabeleceu-se que às três esferas de poder dos entes públicos, devem instalar e manter um Sistema de Controle Interno, hoje denominado UCI, para acompanhar o orçamento em todas as suas fases, assim como o processo da despesa pública, em todos os órgãos da administração pública do $\mathrm{RN}$, e do mesmo modo, os recursos de origem pública, que são movimentados por entidades privadas, devem ter o mesmo tratamento de fiscalização e controle (CONSTITUIÇÃO ESTADUAL RN, 1989).

Com base no estabelecimento no art. 50 da Constituição Estadual, foi aprovada a LC n. ${ }^{\circ}$ 150/1997, que criou e formou a Controladoria Geral do Estado (CGE) e o Sistema Integrado de Controle Interno (SICI), no âmbito do Executivo, visando a fiscalização e controle do patrimônio público, a CONTROL, sendo o órgão centralizador das Unidades de Controle Interno no RN.

Idos mais de 20 anos da criação da Controladoria Geral do Estado, como órgão central responsável pelo exercício do controle interno do Poder Executivo, através da LCE n $150 / 1997$, o SICI passou a ser regido pela nova LCE n⿳ 638/2018, que mudou o Sistema Integrado de Controle Interno (SICI) do Poder Executivo do RN. Assim, geram-se as atividades de Ouvidoria e Corregedoria, no âmbito da CGE, passando o SICI do Poder Executivo a ser um conjunto de órgãos, funções e atividades, composto pela CONTROL, como órgão central, e pelas UCI's, de forma estável, com alcance na administração direta e indireta dos órgãos públicos do RN.

Destarte, a LCE n. ${ }^{\circ} 638 / 2018$, em seu art. $3^{\circ}$, passou a estabelecer as mesmas atribuições do art. 70 da CF-88, no cumprimento das metas previstas na Lei de Diretrizes Orçamentárias (LDO) e no Plano Plurianual (PPP), na execução dos Programas de Governo e dos Orçamentos do Estado, para exercer o controle de legalidade, da legitimidade e da economicidade quanto à qualidade e efetividade dos atos da gestão pública, assim como, a observância da conformidade na aplicação das verbas públicas pelos entes da administração direta e indireta, em que, estendeu-se as funções de correição, auditoria e ouvidoria no art. $4^{\circ}$ desta LC.

A LC no 638/2018, foi regulamentada pelo Decreto Estadual n ${ }^{\circ}$ 28.684/2018 e em conformidade com o art. 33, as Comissões de Controle Interno (CCI) dos órgãos e instituições do Poder Executivo Estadual foram transformadas em UCI, s e ainda no art. 22 estabeleceu que os agentes públicos do quadro efetivo do Estado, membros das UCIs, indicados pelo dirigente do órgão, devem preferencialmente atender aos requisitos de possuir curso superior e que tenha conhecimento sobre finanças públicas.

Por sua vez, o Decreto Estadual no 28.684/2018, no seu art. 29, estabeleceu que os integrantes das UCIs deverão, ter atividade exclusiva na UCI, com o objetivo de promover a segurança, a continuidade dos controles, para que haja eficiência na gestão pública. O Tribunal de Contas do Estado é um órgão que atua na fiscalização das atribuições determinadas no DE $\mathrm{n}^{\circ}$ 28.684/2018, pois na legislação estadual, a LC n ${ }^{\circ} 464 / 2012$, a qual trata sobre a Lei Orgânica do TCE-RN , em seus artigos 147, 148 e 149, já dispunha que as esferas de poder no âmbito Estadual, e dos Municípios devem manter integralmente um SICI, com o cumprimento de 
funções. Destaca-se que os responsáveis pelo Controle Interno respondem solidariamente com os gestores, no tocante as irregularidades detectadas sob a sua responsabilidade.

A Instrução Normativa $n^{\circ}$ 2, da Controladoria Geral do RN, de 1 de outubro de 2018, estabelece, em seu Art. $1^{\circ}$, as competências das UCI, s no âmbito do Executivo Estadual. O Decreto Estadual $\mathrm{n}^{\mathrm{o}} 28.864 / 2018$, em seu artigo $4^{\circ}$, parágrafo único, disciplina que as UCI, $\mathrm{s}$ deverão promover o apoio a gestão, supervisionando as atividades realizadas em seus respectivos órgãos, na gestão integral relacionados ao SICI.

Devido à relevância do trabalho dos sistemas de controle interno no Brasil, o Conselho Federal de Contabilidade (CFC) editou - NBCT 16.8 - Norma Brasileira de Contabilidade Técnica - Controle Interno, que estabelece referenciais de como se promover a gestão do controle interno nas entidades do setor público, desenvolvendo as práticas inerentes ao SICI, facilitando a tomada de decisão dos gestores e promovendo a realização de processos em conformidade com as normas e procedimentos (NBCT 16.8, 2008).

\subsection{ESTUDOS RELACIONADOS SOBRE O TEMA}

Realizou-se uma pesquisa nos principais periódicos, estudos relacionados com o tema, evidenciando os objetivos e resultados encontrados para se realizar um delineamento de como se processaram esses estudos, conforme (Quadro 3).

Quadro 3 - Estudos relacionados ao controle interno em órgãos públicos

\begin{tabular}{|c|c|c|}
\hline Autores & Objetivos & $\begin{array}{r}\text { Resultados da Pesquisa } \\
\end{array}$ \\
\hline $\begin{array}{c}\text { Araújo, Silva e } \\
\text { Lima (2018) }\end{array}$ & $\begin{array}{c}\text { Identificar a contribuição da } \\
\text { controladoria para a } \\
\text { Administração Pública perante a } \\
\text { LRF }\end{array}$ & $\begin{array}{c}\text { Constatou-se que a controladoria municipal, auxilia a gestão, } \\
\text { por meio da fiscalização e controle da execução da despesa } \\
\text { pública, revelando como ferramenta imprescindível para a } \\
\text { eficiência do serviço público. }\end{array}$ \\
\hline $\begin{array}{l}\text { Nascimento et } \\
\text { al. (2015) }\end{array}$ & $\begin{array}{l}\text { Compreender a atuação da UCI } \\
\text { da Justiça Federal de Roraima } \\
\text { no processo da despesa pública }\end{array}$ & $\begin{array}{l}\text { O estudo constatou que a UCI desempenha relevante atividade } \\
\text { na gestão pública, proporcionando os gestores informações } \\
\text { fidedignas, e monitorando os procedimentos administrativos, } \\
\text { para a prestação de serviços com excelência, e ainda, evitando } \\
\text { desvios dos recursos públicos. }\end{array}$ \\
\hline $\begin{array}{l}\text { Cardin et al. } \\
\quad(2015)\end{array}$ & $\begin{array}{l}\text { Averiguar o significado do } \\
\text { controle interno na } \\
\text { Administração Pública de bens e } \\
\text { serviços. }\end{array}$ & $\begin{array}{l}\text { O Controle Interno promove um maior fluxo de informações, } \\
\text { através do monitoramento permanente dos processos, e com } \\
\text { isso atende aos requisitos dos Tribunais de Contas, e ainda } \\
\text { auxilia nas licitações públicas, evitando erros e fraudes, e } \\
\text { assim, promove-se a transparência das verbas públicas. }\end{array}$ \\
\hline Tanaka (2012) & $\begin{array}{l}\text { Promover um debate sobre a e } \\
\text { relevância do Controle Interno } \\
\text { na Administração Pública }\end{array}$ & $\begin{array}{c}\text { Constatou-se a relevância do controle interno como } \\
\text { mecanismo fundamental para evitar desvios de verbas } \\
\text { públicas, e ainda, sugeriu-se nesse estudo a divisão da } \\
\text { Controladoria, em dois setores independentes, retirando a } \\
\text { Auditoria do âmbito da Controladoria, para manter a } \\
\text { independência deste último. }\end{array}$ \\
\hline Holanda (2019) & $\begin{array}{l}\text { Propôs investigar e avaliar a } \\
\text { aderência das estruturas de } \\
\text { governança das UCI's no RN, } \\
\text { através das diretrizes de } \\
\text { governança pública. }\end{array}$ & $\begin{array}{l}\text { No tocante a investigação, a análise dos resultados pelas } \\
\text { dimensões, liderança, estratégia e controle, evidenciaram-se } \\
\text { vulnerabilidades na organização da governança das UCI 's } \\
\text { que comprometem não só a independência e a objetividade } \\
\text { dos integrantes dessas unidades de controle, como a avaliação } \\
\text { de desempenho. }\end{array}$ \\
\hline
\end{tabular}

Fonte: Estudos relacionados - adaptado pelos autores (2019). 
No estudo realizado por Araújo, Silva e Lima (2018) apontam a controladoria como órgão principal para se promover a eficiência no serviço público, no RN, as UCI, s são coordenadas pela Controladoria Geral do Estado (CONTROL), por determinação da Instrução Normativa $n^{\circ} 2 / 2018$.

Há unanimidade na literatura de que as Unidades de Controle Interno promovem para que a execução dos processos na aquisição de bens/serviços dentro dos aspectos da legalidade, constatado através de achados empíricos anteriores (HOLANDA, 2019; ARAÚJO; SILVA, 2018; NASCIMENTO et al., 2015; CARDIN et al., 2015; TANAKA, 2012).

Cardin et al. (2015) acrescenta que o controle interno funciona como um setor de monitoramento, para atender as exigências do Tribunal de Contas do Estado (TCE). Por sua vez, Tanaka (2012), argumenta que pelo princípio da segregação de funções, deve-se segregar em setores distintos, a controladoria e a auditoria, para que não haja perda de independência do órgão fiscalizador, a auditoria, no Rio Grande do Norte, está subordinada a CONTROL, conforme estabelecido na Instrução Normativa $n^{\circ}$ 002/2018.

Já no estudo realizado por Holanda (2019), na sua monografia de conclusão de curso da UFRN, em que realizou um amplo estudo sobre as UCI, s do RN, apontou a existência de fragilidades na estrutura de governança das UCI's, caracterizada, principalmente, pela falta de independência.

\section{METODOLOGIA}

A metodologia utilizada para o desenvolvimento da presente pesquisa delineia-se nos seguintes aspectos, quanto ao objetivo geral, trata-se de pesquisa descritiva, pois, descreveu os atributos de um público ou fenômeno, em que, buscou-se conhecer e descrever a percepção dos gestores sobre a UCI, não havendo interferência sobre os resultados encontrados (FORTE, 2014).

A classificação da abordagem do problema da pesquisa, evidenciou-se quantitativo, pois teve o objetivo de verificar o juízo e condutas claras e conscientes dos respondentes, utilizando instrumento padronizado, no intuito de atingir o objetivo idealizado. Com relação aos procedimentos, configurou-se, como survey, em uma universidade pública no Estado do RN, através da aplicação de questionário, de forma digital e à distância, com perguntas fechadas e respostas padronizadas (GIL, 2002).

A instituição onde se realizou o estudo atua na área educacional do ensino superior, em que possui12 (doze) mil alunos, entre graduação e pós-graduação, localizando-se sua unidade central, em Mossoró-RN. A população reúne gestores que atuam nas diretorias, vice-diretorias, chefia e subchefia de departamento e ainda coordenadores de pós-graduação reunindo uma amostra final de 78 gestores, os quais se disponibilizaram a participar da pesquisa. O motivo da escolha desses gestores se deu por serem estes que realizam as demandas de aquisições e contratações das necessidades existentes na universidade, por isso, intencionou-se verificar como estes percebem a UCI, para a partir desse levantamento, propor-se melhorias.

No tocante à obtenção dos dados, utilizou-se de um questionário com 15 (quinze) questões fechadas, sendo 3 (três) de caracterização dos respondentes e 12 (doze) sobre a UCI, aplicados em fevereiro de 2020, com o objetivo de verificar a percepção dos gestores no tocante a funcionalidade da UCI. Para um melhor entendimento e visualização, as questões da UCI foram reagrupadas em 9 (nove) questões. Segundo Marconi e Lakatos (2009) o questionário é uma ferramenta para coleta de dados que tem como objetivo responder às necessidades de

Revista Eletrônica do Alto Vale do Itajaí - REAVI, v.09, nº 14, p. 016-039, ago. 2020

ISSN: 2316-4190, DOI 10.5965/2316419009142020016 


\section{REAVI}

conhecimento de determinado tema ou caso. Utilizou-se a escala de Likert, na qual respondentes indicaram a influência dos fatores e o grau de escolha, atribuindo independentemente para o fator, com escalas de 1 (um) a 5 (cinco) pontos, onde 1 e 2 são as concordâncias, o 3 representa o neutro, o 4 e 5 representam as discordâncias.

Os dados foram compilados por meio da ferramenta do Google Forms e aplicados no software Statistical Package for the Social Sciences (SPSS), para verificar as frequências absolutas e relativas. Os resultados são expostos em tabelas do software Microsoft Office (Excel e Word), permitindo uma melhor visualização dos achados da pesquisa. Por fim, realiza-se um confronto dos resultados desta pesquisa com os achados de estudos empíricos anteriores.

\section{ANÁLISE DOS RESULTADOS DA PESQUISA}

Após a apresentação da trajetória metodológica desse estudo, passou-se a apresentar os resultados dos questionários. No tocante ao perfil dos entrevistados, para se caracterizar o público no qual se promoveu a pesquisa, expõe-se Tabela 1, com as características indicativas ao perfil dos participantes deste estudo, corresponde ao gênero, faixa etária e tempo de atuação no cargo.

$\mathrm{Na}$ Tabela 1, constatou-se a prevalência dos respondentes do gênero masculino, com $60,26 \%$, superior em relação ao gênero feminino que corresponde a 39,74\%, demonstrando, portanto, uma predominância do gênero masculino nos gestores desse órgão público. Com relação à faixa de idade, evidenciou-se destaque na faixa etária de 25 a 35 anos, com 28 $(35,90 \%)$ respondentes; nas faixas seguintes, (36 a 45 anos e 46 a 55 anos), estas obtiveram o mesmo percentual de 23,08\%, com 18 respondentes em cada faixa. Acima dos 55 anos, 14 servidores $(17,94 \%)$.

Tabela 1 - Perfil dos respondentes

\begin{tabular}{|c|c|c|c|}
\hline \multicolumn{2}{|c|}{ Caracterização da amostra } & Frequência & $(\%)$ \\
\hline & Masculino & 47 & 60,26 \\
\hline Genero & Feminino & 31 & 39,74 \\
\hline \multirow{4}{*}{ Faixa etária } & 25 a 35 anos & 28 & 35,9 \\
\hline & 36 a 45 anos & 18 & 23,08 \\
\hline & 46 a 55 anos & 18 & 23,08 \\
\hline & Acima de 55 anos & 14 & 14,94 \\
\hline \multirow{5}{*}{$\begin{array}{c}\text { Tempo de atuação } \\
\text { no cargo }\end{array}$} & Até 2 anos & 7 & 8,97 \\
\hline & 2 a 4 anos & 5 & 6,41 \\
\hline & 4 a 6 anos & 8 & 10,26 \\
\hline & 6 a 8 anos & 15 & 19,23 \\
\hline & Acima de 8 anos & 43 & 55,13 \\
\hline
\end{tabular}

Fonte: Dados da Pesquisa (2020).

Configurando-se que dos 46 dos respondentes estão na faixa de 25 a 45 anos, evidenciando-se um grupo relativamente jovem no seu quadro funcional. Quanto ao tempo de atuação no cargo como gestores, 43 (55,13\%), atuam há mais de 8 anos na instituição, configurando-se, portanto, um quadro com experiência no órgão, pois esses cargos de direção são ocupados por professores mais antigos nas suas faculdades, em que são estabelecidos por eleição entre os pares.

Nas Tabelas de 2 a 10, apresentam-se as questões relativas à percepção dos gestores sobre a UCI. Para melhor visualização, evidenciam-se os pontos concordantes, discordantes e neutros,

Revista Eletrônica do Alto Vale do Itajaí - REAVI, v.09, n 14, p. 016-039, ago. 2020

ISSN: 2316-4190, DOI 10.5965/2316419009142020016 
por frequência relativa e absoluta, assim como a moda (número que mais se repetiu nas respostas), e a mediana (número de tendência central em um conjunto de dados), nesse caso o item de 1 a 5 que está no centro das respostas.

Inicialmente, na Tabela 2, verificou-se a acuidade dos gestores quanto a seguinte questão: "os procedimentos e instruções devem ser disciplinados e formalizados através de instrumentos eficazes e transparentes que devem ser emitidos pela autoridade competente”.

Tabela 2 - Os procedimentos e instruções devem ser disciplinados e formalizados

\begin{tabular}{c|c|c|c|c|c}
\hline & $\begin{array}{c}\text { Frequência } \\
\text { Absoluta }\end{array}$ & $\begin{array}{c}\text { Frequência } \\
\text { Percentual }\end{array}$ & $\begin{array}{c}\text { Porcentagem } \\
\text { cumulativa }\end{array}$ & Mediana & Moda \\
\hline Discordo Totalmente & 0 & $0 \%$ & $0 \%$ & 4 & 4 \\
\hline Discordo Parcialmente & 7 & $10,25 \%$ & $10,25 \%$ & 4 & 4 \\
\hline Neutro & 5 & $6,41 \%$ & $16,66 \%$ & 4 & 4 \\
\hline Concordo Parcialmente & 42 & $53,85 \%$ & $70,51 \%$ & 4 & 4 \\
\hline Concordo Totalmente & 23 & $29,49 \%$ & $100 \%$ & 4 & 4 \\
\hline Total & $\mathbf{7 8}$ & $\mathbf{1 0 0 \%}$ & & & 4 \\
\hline
\end{tabular}

Fonte: Dados da Pesquisa (2020)

Os dados da Tabela 2 mostram valores relativamente positivos quanto ao nível de conhecimento da UCI e da existência de normas de controle interno. A questão demonstra que 42 dos respondentes $(53,85 \%)$ concordam parcialmente, evidenciando que gestores possuem conhecimento parcial, e apenas $23(29,49 \%)$ afirmam conhecer totalmente a respeito das normas de controle interno da instituição, evidenciando tanto a moda como a mediana no item 4, configurando que a maioria dos respondentes se localizam em torno desse item.

No órgão em estudo, as normas e procedimentos do controle interno são fiscalizadas, através da Unidade de Controle Interno (UCI), e foram estabelecidas pelo Decreto Estadual $\mathrm{n}^{\circ}$ 28.684/2018, e também através de outras instâncias, como CONTROL, instrução Normativa $n^{\circ}$ 002/2018 e ainda pelo TCE-RN, por sua vez, o CFC, através da NBCT - 16.8, promoveu a edição da referida norma com o objetivo de estabelecer um roteiro para orientar a gestão pública com relação às práticas de controle interno.

Por sua vez, Attie (2011) observa que essas as atividades executadas pela entidade estão de acordo com os preceitos legais, pois os órgãos públicos são atrelados ao princípio da legalidade. Observou-se que 54\% dos gestores conhecem parcialmente as normas de controle interno, apesar de que, o controle final fica na responsabilidade da UCI, deve-se promover orientações sobre os processos na instituição, para que os aspectos legais sejam do conhecimento de todos, e principalmente, dos gestores, para que os processos ao chegarem na UCI, já estejam embasados e não precisem de diligências.

Já de acordo com Morais e Teixeira (2016), o controle interno funciona para evitar erros e fraudes, mas, caso passe despercebido pelo processo de controle alguma irregularidade, e futuramente seja detectado em uma instância superior, o gestor será responsabilizado por esse ato, por isso, os gestores devem procurar conhecer integralmente as normas e procedimentos, para evitar que venham a responder processos (ARAÚJO; SILVA; LIMA, 2018; MORAIS, TEIXEIRA, 2016).

Revista Eletrônica do Alto Vale do Itajaí - REAVI, v.09, n 14, p. 016-039, ago. 2020

ISSN: 2316-4190, DOI 10.5965/2316419009142020016 
Dando continuidade, na Tabela 3, evidencia-se o questionamento acerca da relevância da UCI para os gestores na formalização de processos administrativos no âmbito institucional.

Demonstra-se em parte a falta de valorização dos gestores sobre a relevância da UCI, no tocante ao suporte na formalização dos processos administrativos, onde 39 (50\%) concordam parcialmente e $14(18 \%)$ é indiferente ao trabalho realizado pela UCI. Isso demonstra que 61 $(78,21 \%)$ dos gestores desconhecem ou conhece pouco sobre os trâmites internos da UCI, onde apenas $17(22 \%)$ afirmaram conhecer totalmente esses trâmites.

Tabela 3 - Relevância na UCI para os gestores na formalização de processos administrativos

\begin{tabular}{c|c|c|c|c|c}
\hline & $\begin{array}{c}\text { Frequência } \\
\text { Absoluta }\end{array}$ & $\begin{array}{c}\text { Frequência } \\
\text { Percentual }\end{array}$ & $\begin{array}{c}\text { Porcentagem } \\
\text { cumulativa }\end{array}$ & Mediana & Moda \\
\hline Discordo Totalmente & 0 & 0 & 0 & 4 & 4 \\
\hline Discordo Parcialmente & 8 & $10,26 \%$ & $10,26 \%$ & 4 & 4 \\
\hline Neutro & 14 & $17,95 \%$ & $28,21 \%$ & 4 & 4 \\
\hline Concordo Parcialmente & 39 & $50 \%$ & $78,21 \%$ & 4 & 4 \\
\hline Concordo Totalmente & 17 & $21,79 \%$ & $100 \%$ & 4 & 4 \\
\hline Total & $\mathbf{7 8}$ & $\mathbf{7 8}$ & & & 4 \\
\hline
\end{tabular}

Fonte: Dados da Pesquisa (2020)

Conforme análises das Tabelas 2 e 3 , os resultados apresentam a necessidade da instituição de informar sobre as diretrizes da UCI internamente, bem como promover a atenção necessária às informações relevantes evidenciadas pela UCI que podem ser úteis para a tomada de decisão dos gestores. De acordo com a NBC 16.8 (item 10) salienta-se que o controle interno proporciona segurança, por promover informações verídicas, organizadas pela contabilidade e, ainda, demonstrar a efetividade das normas pelos profissionais no tocante ao alcance dos objetivos propostos pelas instituições.

Esses achados corroboram o com e estudo de Marschner, Sommer e Welter (2017), onde destacam que o controle interno observa o andamento e controle processual correto dos setores envolvidos na gestão pública, pois os gestores não poderão alegar falta de desconhecimento da legislação. Constata-se ainda, em relação ao sistema COSO, em que o ambiente de controle deve delinear o ritmo da organização influenciando a consciência sobre a relevância do controle interno para as pessoas, por essa variável, demonstra-se essa vulnerabilidade (GATTRINGER; MARINHO, 2020; SOARES; RODRIGUES JÚNIOR, 2019).

$\mathrm{Na}$ Tabela 4 apresenta-se o resultado da quarta questão, a qual busca identificar entre os gestores se estes veem a UCI como um órgão de controle interno útil para evitar demandas processuais do TCE-RN e do MP-RN. 


\section{REAVI}

Tabela 4 - Percepção dos gestores sobre a UCI como um órgão de controle interno útil

\begin{tabular}{c|c|c|c|c|c}
\hline & $\begin{array}{c}\text { Frequência } \\
\text { Absoluta }\end{array}$ & $\begin{array}{c}\text { Frequência } \\
\text { Percentual }\end{array}$ & $\begin{array}{c}\text { Porcentagem } \\
\text { cumulativa }\end{array}$ & Mediana & Moda \\
\hline Discordo Totalmente & 2 & $3,85 \%$ & $3,85 \%$ & 5 & 5 \\
\hline Discordo Parcialmente & 4 & $5,13 \%$ & $8,98 \%$ & 5 & 5 \\
\hline Neutro & 5 & $6,41 \%$ & 15,395 & 5 & 5 \\
\hline Concordo Parcialmente & 12 & $15,38 \%$ & 30,77 & 5 & 5 \\
\hline Concordo Totalmente & 54 & $69,23 \%$ & $100 \%$ & 5 & 5 \\
\hline Total & $\mathbf{7 8}$ & $\mathbf{1 0 0 \%}$ & & & 5 \\
\hline
\end{tabular}

Fonte: Dados da Pesquisa (2020).

Os resultados na Tabela 4 evidenciaram que no item de concordância, $12(15,38 \%)$ afirmaram parcialmente e $54(69,23 \%)$ totalmente, quanto a UCI ser uma ferramenta de controle para se evitar diligências dos órgãos de controle, como, o TCE-RN e Ministério Público Estadual. Apesar dos respondentes desconhecerem as normas e procedimentos da UCI, entendem que a mesma funciona como um órgão de controle para se evitar processos do TCE e MP/RN. Esse mesmo entendimento foi observado por Cardin et al. (2015), em estudo realizado no Tribunal de Justiça de Roraima, em que os entrevistados evidenciaram que o controle interno objetiva atender solicitações e regulamentos processuais, principalmente do TCE.

O Tribunal de Contas do Estado, por meio da Lei complementar no 464/2012 e a Controladoria Geral do Estado (CONTROL) por meio da Instrução Normativa $n^{\circ}$ 002/2018, disciplinam sobre como os poderes do Estado devem atuar nos seus controles internos, assim, observa-se que as legislações existem e estão em vigor, e os servidores públicos têm o dever de segui-las, não podendo alegar desconhecimento. $\mathrm{Na}$ LC $\mathrm{n}^{\circ} 464 / 2012$, no art. 148, inciso I, destaca-se que o TCE poderá por iniciativa, ou solicitação do Tribunal, instaurar auditoria em qualquer órgão do Estado do RN, e no art. 149 deste decreto, evidencia que os responsáveis pelo controle interno que não prestarem informações sobre irregularidades ocorridas ao TCE, serão responsabilizados solidariamente.

Esse entendimento de que a UCI funciona como um órgão fiscalizador, para evitar problemas a posteriori dos gestores junto ao tribunal de contas TCE e do Ministério Público, está correto, mas a UCI atua principalmente de forma antecedente, em que os processos são monitorados, para que não tramitem em desacordo com as normas e procedimentos do órgão; assim, se algo foi detectado junto ao TCE e ao MP, significa que houve falha do controle interno, demonstrando-se desconhecimento dos gestores sobre a forma de atuação da UCI (CARDOSO; ESTRELA, 2018; CARDIN et al., 2015; TANAKA, 2012).

Conforme a Tabela 5, evidenciou-se a quinta questão, com o objetivo de verificar a percepção dos gestores sobre a independência da UCI, buscando-se saber entre os gestores se estes constatam a segregação de funções na UCI. 


\section{REAVI}

Tabela 5 - Independência e segregação de funções na UCI

\begin{tabular}{c|c|c|c|c|c}
\hline & $\begin{array}{c}\text { Frequência } \\
\text { Absoluta }\end{array}$ & $\begin{array}{c}\text { Frequência } \\
\text { Percentual }\end{array}$ & $\begin{array}{c}\text { Porcentagem } \\
\text { cumulativa }\end{array}$ & Mediana & Moda \\
\hline Discordo Totalmente & 7 & $10,26 \%$ & $10,26 \%$ & 3 & 3 \\
\hline Discordo Parcialmente & 12 & $15,38 \%$ & $25,64 \%$ & 3 & 3 \\
\hline Neutro & 35 & $44,87 \%$ & $70,51 \%$ & 3 & 3 \\
\hline Concordo Parcialmente & 23 & $29,49 \%$ & $100 \%$ & 3 & 3 \\
\hline Concordo Totalmente & 0 & 0 & 0 & 3 & 3 \\
\hline
\end{tabular}

Fonte: Dados da Pesquisa (2020).

De acordo com a Tabela 5, verifica-se que a alternativa com maior número de respondentes foi o item neutro $35(44,87 \%)$; os discordantes, $19(25,64 \%)$ entendem que a segregação de funções não é observada e 23 (20,49\%) concorda parcialmente, e nenhum respondente concordou totalmente. Entretanto, para a literatura, a segregação de funções é um dos principais princípios da auditoria, em que a mesma pessoa ou setor, não deve realizar várias atividades ao mesmo tempo; deve-se segrega-las para evitar fraudes (CREPALDI; BIACHI, 2015).

Em pesquisa de Tanaka (2012), nos seus resultados, recomendou-se dividir a Unidade Controladoria em dois setores distintos, Controladoria e Auditoria, apesar desse órgão, não realizar a atividade de Auditoria, sendo essa prerrogativa da CONTROL, esse órgão centraliza o controle das UCI's e realiza auditoria concomitantemente, nesse caso, a independência da auditoria estaria comprometida (LEI COMPLEMENTAR nº 638/2018).

Constata-se que em vários órgãos do Estado para se ter maior autonomia, os membros da UCI são eleitos pelos seus pares. No caso específico deste órgão, o Diretor Geral nomeia o presidente da UCI, mas o TCE é quem realiza a aprovação dos seus membros e dá o atesto para que os servidores possam fazer parte da UCI, através de um exame realizado no TCE-RN, em que se deve obter nota 7,0 (sete) em uma avaliação, para sua aprovação, em que, para uma UCI ter independência e autonomia de atuação, precisa de um órgão neutro para ser o seu responsável máximo. O LCE n. 638/2018, no art. 22, § 1 e 2, evidencia que "as Unidades de Controle Interno serão compostas por servidores públicos indicados pelo dirigente do Órgão ou Entidade e designados após aprovados pela CONTROL". Essa aprovação da CONTROL se refere ao exame realizado pelo TCE.

Apesar dos gestores apontarem negativamente para a segregação de funções no âmbito da instituição, as legislações coadunam com a segregação, onde se proíbe que o agente que atue na UCI possa atuar em outro setor, devendo ter seu tempo integral para essa atividade, e as unidades de controle monitoram esses agentes, para verificarem sua aptidão e competência para o cargo (LEI COMPLEMENTAR n ${ }^{\circ}$ 638/2018).

Na sexta questão buscou-se obter a percepção dos respondentes sobre o principal objetivo da UCI, indagando-se se este seria o resguardo do Patrimônio Público, conforme demonstra a Tabela 6. 


\section{REAVI}

Tabela 6 - Objetivo principal da UCI

\begin{tabular}{c|c|c|c|c|c}
\hline & $\begin{array}{c}\text { Frequência } \\
\text { Absoluta }\end{array}$ & $\begin{array}{c}\text { Frequência } \\
\text { Percentual }\end{array}$ & $\begin{array}{c}\text { Porcentagem } \\
\text { cumulativa }\end{array}$ & Mediana & Moda \\
\hline Discordo Totalmente & 0 & $0 \%$ & 0 & 4 & 4 \\
\hline Discordo Parcialmente & 3 & $9,7 \%$ & $9,7 \%$ & 4 & 4 \\
\hline Neutro & 0 & $0 \%$ & $9,7 \%$ & 4 & 4 \\
\hline Concordo Parcialmente & 57 & $74,2 \%$ & $83,9 \%$ & 4 & 4 \\
\hline Concordo Totalmente & 6 & $16,1 \%$ & $100 \%$ & 4 & 4 \\
\hline Total & $\mathbf{7 8}$ & $\mathbf{1 0 0 \%}$ & & &
\end{tabular}

Fonte: Dados da Pesquisa (2020).

Verificou-se que $63(90 \%)$ viram a UCI como um órgão que resguarda o patrimônio público, através do estabelecimento de métodos e protocolos postos. Apesar de os gestores não terem compreensão das diretrizes da UCI, creem que esse órgão resguarda o patrimônio público.

Na Lei n ${ }^{\circ} 638 / 2018$, art. $21^{\circ}$, inciso I e II, descreve que, compete às UCI's e nos Órgãos e Entidades do Executivo, exercer os controles relacionados às atividades institucionais ou administrativas, para atender os ditames legais, protegendo a dilapidação do patrimônio público, na busca pela excelência na prestação de serviços à sociedade.

$\mathrm{Na}$ análise dos estudos já realizados sobre esse tema, é unanimidade entre os autores o conhecimento de que as Unidades de Controle Interno têm como finalidade principal resguardar o patrimônio público (HOLANDA, 2019; ARAÚJO; SILVA, 2018; NASCIMENTO et al., 2015; CARDIN et al., 2015; TANAKA, 2012).

O controle interno atua preventivamente para proteger o patrimônio público, garantindo a execução dos processos da despesa pública, segundo Peter e Machado (2009). Neste contexto, sua função exercida no âmbito do poder público, por meio da Controladoria, tem a finalidade de controlar os atos da gestão financeira, orçamentária, patrimonial e operacional. A CF 88, no art. 70, evidencia a controle patrimonial dos entes federados, através do controle interno (UCI) e controle externo (TCE) (NASCIMENTO et al., 2015; CARDIN et al., 2015; TANAKA, 2012).

Tabela 7 - Entendimento e a existência de instruções normativas dos processos

\begin{tabular}{c|c|c|c|c|c}
\hline & $\begin{array}{c}\text { Frequência } \\
\text { Absoluta }\end{array}$ & $\begin{array}{c}\text { Frequência } \\
\text { Percentual }\end{array}$ & $\begin{array}{c}\text { Porcentagem } \\
\text { cumulativa }\end{array}$ & Mediana \\
\hline Discordo Totalmente & 22 & $28,21 \%$ & $28,21 \%$ & 2 \\
\hline Discordo Parcialmente & 40 & $51,28 \%$ & $79,49 \%$ & 2 \\
\hline Neutro & 7 & $8,97 \%$ & $88,46 \%$ & 2 \\
\hline Concordo Parcialmente & 5 & $6,41 \%$ & $94,87 \%$ & 2 \\
\hline Concordo Totalmente & 4 & $5,13 \%$ & $100 \%$ & 2 \\
\hline
\end{tabular}

Fonte: Dados da Pesquisa (2020)

Revista Eletrônica do Alto Vale do Itajaí - REAVI, v.09, no 14, p. 016-039, ago. 2020

ISSN: 2316-4190, DOI 10.5965/2316419009142020016 
Constatou-se, na Tabela 7 , que 40 dos respondentes $(51,28 \%)$ discordam parcialmente e $22(28,21 \%)$ totalmente, representando que $80 \%$ dos gestores desconhecem o funcionamento e os trâmites processuais da Unidade de Controle Interno, contra apenas 9 (11,43\%) daqueles que afirmaram terem conhecimento.

Esse desconhecimento dos gestores sobre os trâmites processuais dentro do modelo COSO enquadra-se nas atividades de controle, que são as políticas, normas, procedimentos existentes, diretrizes que devem ser seguidas como padrão, nesse item esse órgão não atende esse requisito (GATTRINGER; MARINHO, 2020; SOARES; RODRIGUES JÚNIOR, 2019).

Destaca-se em estudos acadêmicos sobre entidades públicas, especialmente por estarem atreladas ao princípio da Legalidade, que os gestores devem buscar seguir as normas e procedimentos de controle interno do órgão público, promovendo a utilização dos recursos públicos eficientemente e com transparência (MARSCHNER; SOMMER; WELTER, 2018; Nascimento et al., 2015).

Dessa forma, corrobora também Morais e Teixeira (2016), quando destacam que o controle interno funciona para evitar erros e fraudes, e os gestores devem procurar conhecer integralmente as normas e procedimentos, para evitar que sejam penalizados (ARAÚJO; SILVA; LIMA, 2018; MORAIS, TEIXEIRA, 2016).

Diante disso, procurou-se verificar se os gestores receberam opiniões sobre inconsistências constatadas pela UCI em processos em que os mesmos atuaram como solicitantes, conforme Tabela 8.

Tabela 8 - Inconsistências constatadas pela UCI em processos

\begin{tabular}{c|c|c|c|c|c}
\hline & $\begin{array}{c}\text { Frequência } \\
\text { Absoluta }\end{array}$ & $\begin{array}{c}\text { Frequência } \\
\text { Percentual }\end{array}$ & $\begin{array}{c}\text { Porcentagem } \\
\text { cumulativa }\end{array}$ & Mediana & Moda \\
\hline Discordo Totalmente & 18 & $23,08 \%$ & $23,08 \%$ & 2 & 2 \\
\hline Discordo Parcialmente & 32 & $41,03 \%$ & $64,11 \%$ & 2 & 2 \\
\hline Neutro & 15 & $19,23 \%$ & $83,34 \%$ & 2 & 2 \\
\hline Concordo Parcialmente & 6 & $7,92 \%$ & $91,26 \%$ & 2 & 2 \\
\hline Concordo Totalmente & 7 & $8,74 \%$ & $100 \%$ & & 2 \\
\hline Total & $\mathbf{7 8}$ & $\mathbf{1 0 0 \%}$ & & & 2 \\
\hline
\end{tabular}

Fonte: Dados da Pesquisa (2020)

Na Tabela 8, ficou evidenciado que a UCI não realiza feedback com os gestores do órgão a respeito das não-conformidades constatadas, pois, assim, poderá haver uma sistematização dos procedimentos e evitar que os processos fiquem parados por detecção de inconsistências, como falta de assinaturas, falta de documentos, certidões pendentes, etc. Nas legislações analisadas sobre a UCI, não se encontrou de forma objetiva que se aponta para o feedback das inconsistências apresentadas, a qual evidencia-se de forma subjetiva.

O CFC, através da NBCT do setor público sobre controle interno, através da NBCT 16.8, estabelece que o mesmo deve promover informações para os gestores, com o objetivo de contribuir para a eficiência da entidade, se o trâmite processual e demorado, prejudica o processo 
de tomada de decisão dos gestores, que poderiam rapidamente, promover decisões diferenciadas, desde que tenham à sua disposição as informações.

O controle interno de um órgão público pode colaborar nos seus relatórios para as inconsistências verificadas, para que erros não se repitam, pois, o objetivo não é só de apontar os erros, mas sim de como saná-los. A ausência de feedback apontada pelos respondentes é primordial para que a UCI possa atuar com efetividade (CREPALDI; BIACHI, 2015).

Constata-se no COSO, na dimensão informação e comunicação, onde se processa a identificação e captura, e troca de informações, elemento vital para o processo de melhoria contínua, e ainda, no monitoramento dos processos, onde se qualifica a eficiência dos sistemas de controles internos, e essa avaliação fica comprometida, pois, se não existe feedback dos registros dos processos, não se pode avalia-los (GATTRINGER; MARINHO, 2020; SOARES; RODRIGUES JÚNIOR, 2019).

Por fim, buscou-se saber dos respondentes sobre o tempo de trâmites dos processos da UCI, com relação a tempestividade, ou seja, se estão acontecendo dentro de prazo razoável, com dinamismo e rapidez, conforme demonstrado na Tabela 9.

De acordo com a Tabela 9, constatou-se que 66 (84,58\%) concordam parcialmente, evidenciando que uma parcela representativa dos gestores destaca que no quesito trâmite processual, a UCI está com demora na liberação dos processos. Isso promove atraso nas aquisições e contratações, desencadeando problemas na prestação de serviços de qualidade para à sociedade.

Tabela 9 - Tempo de trâmites dos processos da UCI

\begin{tabular}{c|c|c|c|c|c}
\hline & $\begin{array}{c}\text { Frequência } \\
\text { Absoluta }\end{array}$ & $\begin{array}{c}\text { Frequência } \\
\text { Percentual }\end{array}$ & $\begin{array}{c}\text { Porcentagem } \\
\text { cumulativa }\end{array}$ & Mediana & Moda \\
\hline Discordo Totalmente & 0 & 0 & 0 & 4 & 4 \\
\hline Discordo Parcialmente & 0 & 0 & 0 & 4 & 4 \\
\hline Neutro & 26 & $33,3 \%$ & $33,34 \%$ & 4 & 4 \\
\hline Concordo Parcialmente & 40 & $51,28 \%$ & $84,62 \%$ & 3 & 4 \\
\hline Concordo Totalmente & 12 & $15,38 \%$ & $100 \%$ & 4 & 4 \\
\hline Total & $\mathbf{7 8}$ & $\mathbf{1 0 0 \%}$ & & & 4 \\
\hline
\end{tabular}

Fonte: Dados da Pesquisa (2020)

Na ótica de Gerigk, Clemente e Ribeiro (2014), os gestores públicos necessitam de um suporte eficiente para promoverem as mudanças ocorridas no ambiente organizacional para realizar um serviço de qualidade para a população; assim, no modelo COSO, se esse órgão utiliza o monitoramento, que é o meio de avaliação da conformidade dos controles internos, fatos dessa natureza, como falta de tempestividade nos trâmites processuais, seriam detectados (GATTRINGER; MARINHO, 2020; SOARES; RODRIGUES JÚNIOR, 2019).

Corroborando Nascimento et al. (2015) esclarecem que a correta execução dos procedimentos administrativos visa a melhoria dos serviços prestados, evitando desperdícios e prejuízos para o serviço público, pois o atraso em uma aquisição, por exemplo, pode promover a má qualidade na prestação de ações sociais para os cidadãos. 


\section{REAVI}

\section{CONSIDERAÇÕES FINAIS}

O estudo estabeleceu como objetivo geral analisar a percepção dos gestores de um órgão público no RN no tocante ao conhecimento e procedimentos da Unidade de Controle Interno (UCI), órgão de fiscalização e controle existentes nos órgãos públicos do RN, para, a partir dessas percepções, se promoverem melhoras no funcionamento desse relevante órgão de controle estadual. Nas discussões, buscou-se referenciar o controle interno, através da ótica púbica, em que se evidenciaram: aspectos introdutórios, a ligação do controle interno e a administração pública, destacou-se o modelo de gerenciamento de controle interno COSO e percorreram-se as legislações federais e estaduais do RN, para se promover o embasamento teórico.

A pesquisa atendeu ao seu objetivo quanto a verificar a percepção dos gestores de um órgão público do RN, no tocante ao funcionamento e trâmites da UCI, em que, destacaram na pesquisa: falta de conhecimento integral das normas e procedimentos, onde somente $30 \%$ relataram conhecer as legislações internas, fato este que pode gerar problemas futuros para esses gestores, caso processos tramitem com erros. Ressalte-se ainda $30 \%$ dos entrevistados evidenciaram falta de consciência relacionada à significância do controle interno, sendo que esse item é uma das medidas controladas pelo sistema COSO.

No tocante as ações antecedentes e subsequentes da UCI, 75\% dos gestores visualizam a UCI como um órgão de controle para evitar problemas a posteriori, isto é, evitar demandas no TCE e Ministério Público, e não percebem que a UCI atua em todas as fases, evitando a tramitação de processos com vícios e erros.

Com relação à segregação de funções, $75 \%$ dos gestores apontaram que esse princípio não é cumprido no órgão, denotando desconhecimento dos requisitos para se atuar na UCI. Nos questionamentos, $80 \%$ destacaram desconhecer as normas e procedimentos de controle interno, evidenciando uma falha, pois o desconhecimento desses gestores promove mais diligências pela UCI, pelo fato de os gestores encaminharem processos em desconformidade com as legislações.

Evidenciou-se ainda a falta de feedback da UCI para os gestores, em que $83 \%$ dos respondentes demonstraram ser deficiente essa variável na UCI. Ressalte-se que essa prática não promove a melhoria contínua dos processos, pois se os operadores não sabem os erros, irão continuar praticando, inviabilizando, portanto, a avaliação de desempenho da UCI por não se ter medições. Destaque-se ainda $84 \%$ dos gestores demonstraram que existe demora nos trâmites processuais, destacando-se a necessidade de se criar protocolos com estabelecimentos de prazos para permanência de processos na UCI.

$\mathrm{Na}$ comparação com estudos anteriores, Holanda (2019), destacou a fragilidade na estrutura de governança da UCI, que comprometem as atividades do controle interno. Esses resultados coadunam com essa pesquisa, em que fragilidades foram verificadas, e observa-se a preocupação de atender as legislações e dificuldades de gestão das UCI's.

Em outra pesquisa, Gattringer e Marinho (2020), em 295 municípios, sobre a ótica do modelo COSO sobre a gestão do controle interno, os autores destacaram deficiência nas dimensões ambiente de controle e informação, e comunicação. No presente estudo, detectaramse também problemas nessas duas dimensões, na primeira relacionada a falta de conscientização dos gestores da relevância da UCI e na segunda relacionada a falta de feedback da UCI, e ainda se verificaram problemas relacionados as atividades de controle, no tocante as deficiências sobre normas e procedimentos.

Apesar de demonstrar achados relevantes, o estudo limita-se tendo em vista que foi realizado apenas em um órgão público, fato este que não se pode generalizar seus resultados.

Revista Eletrônica do Alto Vale do Itajaí - REAVI, v.09, no 14, p. 016-039, ago. 2020

ISSN: 2316-4190, DOI 10.5965/2316419009142020016 
Entretanto, o artigo traz contribuições, do ponto de vista social, destaca-se a necessidade desse órgão público direcionar estratégias gerenciais para resolver os problemas apresentados na gestão da UCI. Do ponto de vista acadêmico, a pesquisa avança na discussão e ampliação dos debates sobre o tema, pois a Unidade de Controle Interno faz parte das estruturas dos órgãos públicos do Brasil, e os problemas evidenciados podem servir de direcionador para promover melhorias em outras UCI's. Dessa forma, sugere-se a replicação dos procedimentos metodológicos da presente pesquisa em outros órgãos públicos, podendo realizar comparativos entre instituições.

\section{REFERÊNCIAS}

ARAÚJO, J. C. O.; SILVA, K. S da.; LIMA, F. G. V. Controladoria na gestão pública: um estudo na unidade de controle interno (UCI) do município de Castanhal sob a ótica da Lei de Responsabilidade Fiscal (LRF). Brazilian. Journal of Develop., Curitiba, v. 4, n. 7, edição especial, p. 3755-3772, nov. 2018. Disponível em:

http://www.eventos.ufu.br/contufu2017\#publicacoes Acesso em: 14 dez 2019.

ATTIE, William. Auditoria: conceitos e aplicações. 6. ed. São Paulo: Atlas, 2011.

BARDIN, L. Análise de conteúdo. Lisboa: Edições 70, 2011.BRASIL. Constituição Federal Brasileira. Brasília, 1988. Disponível em: http://www.planalto.gov.br/ccivil_03/Constituicao.htm. Acesso em: 20/02/2020.

BEUREN, I. M.; ZONATTO, V. C. S. Perfil dos artigos sobre controle interno no setor público em periódicos nacionais e internacionais. Revista da Administração Pública, Rio de Janeiro, v. 48, n. 5, p.1135-1163, set./out. 2014. http://dx.doi.org/10.1590/0034-76121527

BRANDÃO, S. P. Impacto do controlo interno no controlo externo: pesquisa exploratória. 2012. 122 f. Dissertação (Mestrado em Contabilidade) - Instituto Superior de Contabilidade e Administração, Universidade de Aveiro, Aveiro, 2012. Disponível em: http://www.aeca1.org/xvencuentroaeca/cd/62d.pdf Acesso em: 12 jan. 2020.

BRASIL. Decreto-Lei 200/1967. Disponível em: http://www.planalto.gov.br/ccivil_03/decretolei/del0200.htm. Acesso: 14 de jan. 2020.

BRASIL. Lei Federal n 4.320, de 17 de março de 1964. Estabelece Normas Gerais de direito financeiro para elaboração e controle dos orçamentos e balanços da União, dos Estados, dos Municípios e do Distrito Federal. Disponível em:

http://www.planalto.gov.br/ccivil_03/leis/14320.htm. Acesso em: 28 jan. 2020.

BRASIL. Lei Complementar Federal $n^{0}$ 101, de 4 de maio de 2000. Estabelece normas de finanças Públicas voltadas para a responsabilidade na gestão fiscal. Brasília. Disponível em: http://www.planalto.gov.br/ccivil_03/leis/lcp/lcp101.htm. Acesso em: 12 jan. 2020.

BRASIL. Lei Complementar Estadual $n^{0}$ 150, de 9 de janeiro de 1997. Institui o Sistema Integrado de Controle Interno do Poder Executivo, cria e organiza a Controladoria Geral do 


\section{REAVI}

Estado do Rio Grande do Norte e dá outras providências. Disponível em:

http://adcon.rn.gov.br/ACERVO/control/DOC/DOC000000000010406.PDF Acesso em: 14 fev. 2020.

BRASIL, Lei Complementar Estadual no 157, de 23 de dezembro de 1997. Disponível em: http://adcon.rn.gov.br/ACERVO/control/DOC/DOC000000000010413.PDF acesso em: 11 jan. 2020.

BRASIL, Decreto 13.745, de 16 de janeiro de 1988. Aprova o regimento Interno da Controladoria Geral do Estado do Rio Grande do Norte - CONTROL, e dá outras providências. Disponível em: http://adcon.rn.gov.br/ACERVO/control/DOC/DOC000000000010418.PDF Acesso 28 fev. 2020.

BRASIL, Lei Complementar Estadual no 464, de 5 de janeiro de 2012. Dispõe sobre a Lei Orgânica do Tribunal de Contas do Estado do Rio Grande Norte. Disponível em: http://www.tce.rn.gov.br/as/DOE/Legislacao/Lei_Complementar_n_4642012.pdf. Acesso em: 14 fev. 2020.

BRASIL, Lei Complementar Estadual no 638 de 28 de junho de 2018. Dispõe sobre o Sistema Integrado de Controle Interno do Poder Executivo do Rio Grande do Norte. Disponível em: http://www.diariooficial.rn.gov.br/dei/dorn3/docview.aspx?id_jor=00000001\&data=20180629\&i d_doc $=613830$. Acesso em: 22 fev. 2020.

BRASIL, Decreto n. ${ }^{\circ}$ 3.591, de 6 de setembro 2000. Dispõe sobre o Sistema de Controle Interno do Poder Executivo Federal e de outras providências. Presidência da República. Casa Civil. Subchefia para Assuntos Jurídicos. Disponível em: http://www.planalto.gov.br/ccivil_03/decreto/D3591.htm. Acesso em: 23 jan. 2020.

BRASIL, Decreto $\mathrm{n}^{\circ}$ 28.684, de 31 de dezembro de 2018. Sistema Integrado de Controle Interno do Poder Executivo do Rio Grande do Norte, Lei Complementar Estadual $n^{\circ}$ 638, de 28 de junho de 2018. Disponível em: http://webdisk.diariooficial.rn.gov.br/Jornal/12019-0101.pdf. Acesso em: 11 jan. 2020.

CALIXTO, G. E.; VELÁSQUEZ, M. D. P. Sistema de controle interno na administração pública federal. Revista Eletrônica de Contabilidade. Jul/2015. Disponível em:

https://periodicos.ufsm.br/contabilidade/article/view/63/3660 Acesso em: 20 dez 2019.

CARDIN, S.A.; GUIMARÃES, F. R. F. B.; BARBOSA, M. V.; MONTEIRO, A. de S.; LOPES, P. de L. Controle interno na administração pública como ferramenta para economicidade de processos. Simpósio de Excelência em Tecnologia, 2015. Disponível em: file:///C:/Users/slpsc/Documents/Artigos/UCI\%20DA\%20UERN/35622398.pdf. Acesso em: 14 jan. 2020.

CARDOSO, C. I. X. da S.; ESTRELLA, W. M. A. de M. Conflitos no ambiente das instituições públicas um estudo bibliométrico de produções acadêmicas nacionais entre 2010 e 2014. Revista 
Práticas em Gestão Pública Universitária, ano 2, v. 2, n. 1, jan.-jun. 2018. Disponível em: https://revistas.ufrj.br/index.php/pgpu/article/view/4275/10982 Acesso em: 23 jan. 2020.

CASTRO, Domingos Poubel de. Auditoria, contabilidade e controle interno no setor público: integração das áreas do ciclo de gestão: contabilidade, orçamento e auditoria, e organização dos controles internos, como suporte à governança corporativa. 3.ed. São Paulo: Atlas 2010.

COOPER, D. J.; MORGAN, W. Case study research in accounting. Accounting Horizons, v. 22, n. 2, p. 159-178, 2008. https://doi.org/10.2308/acch.2008.22.2.159

CREPALDI, Michelle Rossini; BIANCHI, Vinicius Rafael. A importância da auditoria interna. Comunicação \& Mercado: Revista Internacional de Ciências Sociais Aplicadas, Dourados, v. 4, n. 10, p.96-104, dez. 2015. Disponível em:

https://www.unigran.br/dourados/mercado/paginas/arquivos/edicoes/10/8.pdf Acesso em: 9 jan. 2020.

ELIAS, L.; DALMAU, M. B. L; BERNARDINI, I. de S. A importância da gestão de conflitos nas relações de trabalho - Estudo de caso na Secretaria de Saúde de Biguaçu/SC, 2013. Disponível em:http://gsp.cursoscad.ufsc.br/wp/wpcontent/uploads/2013/03/Artigo_07.pdf. Acesso em: 10 fev. 2020.

FARIAS, R. P.; DE LUCA, M. M. M.; MACHADO, M. V. V.A metodologia COSO como ferramenta de gerenciamento dos controles internos. Contabilidade, Gestão e Governança, Brasília, v. 12, n. 3, p. 55-71, set/dez 2009. Disponível em:

https://www.revistacgg.org/contabil/article/view/132 acesso em: 11 jan. 2020.

FORTE, Sérgio Henrique Arruda Cavalcante. Manual de elaboração de Tese, Dissertação e Monografia. 4. ed. Fortaleza: Gráfica UNIFOR, 2004. 49 p. Disponível em:

https://www.hugoribeiro.com.br/biblioteca-digital/UNIFOR-Normas.pdf Acesso em; $21 \mathrm{fev}$. 2020.

GATTRINGER, J. L.; MARINHO, S. V; O uso do COSO na Administração Pública: um estudo nos municípios Catarinenses. Enfoque: Reflexão Contábil, Paraná, v. 39, n.1, p. 75-95, jan./abr, 2020. https://doi.org/10.4025/enfoque.v39i1.44412

GERIGK, Wilson; CLEMENTE, Ademir; RIBEIRO, Flávio. O Padrão do Endividamento Público nos Municípios Brasileiros de Porte Médio Após a Lei de Responsabilidade Fiscal. Revista Ambiente Contábil - UFRN - Natal-RN. v. 6.n. 1, p. 122 - 140, jan./jun. 2014. Disponível em: https://periodicos.ufrn.br/ambiente/article/view/4128 Acesso em: 28 jan. 2020.

GIL, Antônio Carlos. Como elaborar projetos de pesquisa. 4. ed. São Paulo: Atlas, 2002.

HOLANDA, Gilderlanio Alves. Diagnóstico das unidades de controle interno do poder executivo do Estado do Rio Grande do Norte. Monografia de Graduação. Curso Ciências Contábeis, UFRN, Natal-RN, 2019. Disponível em: 


\section{REAVI}

file:///C:/Users/slpsc/Documents/Artigos/UCI\%20DA\%20UERN/MONOGRAFIA_GILDERLA NIO.pdf. Acesso em: 25 jan. 2020.

LOPES, F. dos S.; SILVA MARIA, V. D. de C.; SILVA, M. S.; CRUZ, F. C. da. Uma luz na escuridão: a evidenciação contábil sob a égide da Lei de Responsabilidade Fiscal. Revista Principia, Divulgação Científica e Tecnológica do IFPB, n. 27, João Pessoa, 2015. Disponível em: https://periodicos.ifpb.edu.br/index.php/principia/article/view/320. Acesso em: 14 jan. 2020.

MARSCHNER, P. F.; SOMMER, A. T.; WELTER, L. M. Sistema de controle interno na gestão pública de um município de pequeno porte. Revista Eletrônica do Alto Vale do Itajaí REAVI, v. 7, n. 10, p. 48-61, jun. 2018. https://doi.org/10.5965/2316419007102018048

MEIRELES, Alexandre; PETINGA, Daniel. Manual de legislação tributária estadual. Salvador: Editora Juspodivm, 2018.

MELO, J.M.; SANTOS, F.; GIROTTO, M. Gestão pública responsável: uma abordagem do sistema CFC/CRCs. Brasília: Juruá, 2011. Disponível em: http://portalcfc.org.br/wordpress/wpcontent/uploads/2013/01/livro_gestao.pdf . Acesso em: 14 fev. 2020.

MORAIS, Leonardo da Silva; TEIXEIRA, Maria Gracinda Carvalho. Interfaces da Accountability na Administração pública Brasileira: análise de uma experiência na auditoria geral do Estado do Rio de Janeiro. REAd, Porto Alegre, no 1, p. 77-105, Jan/abril. 2016. http://dx.doi.org/10.1590/1413-2311.014162016.62768

NASCIMENTO, C. F.; HOFFMANN, E.; FERREIRA, M. A. de A.; FILHO, F. C da C. A importância do controle interno na avaliação das despesas públicas da Justiça Federal de Roraima. Revista de Administração de Roraima-UFRR, Boa Vista, Vol. 5 n. 2, p.214-236, jul./dez. 2015. http://doi:10.18227/2237-8057rarr.v5i2.2647

NBC T 16.8 - Norma Brasileira de Contabilidade Técnica - Controle Interno. Conselho Federal de contabilidade. 2008. Disponível em:

http://www1.cfc.org.br/sisweb/sre/detalhes_sre.aspx?Codigo=2008/001135. Acesso em: 12 nov. 2019.

PETER, Maria da Glória Arrais e MACHADO, Marcos Vinícius Veras. Manual de Auditoria Governamental. $1^{\circ}$ ed., 4. reimpr. -São Paulo: Atlas, 2009.

SILVA, S. L. P. O aglomerado Produtivo da Indústria Salineira do RN. Tese de Doutorado. Programa PPGEO. Universidade Federal de Pernambuco. 2019. Disponível em: https://repositorio.ufpe.br/bitstream/123456789/34410/1/TESE\%20Sergio\%20Luiz\%20Pedrosa \%20Silva.pdf Acesso em: 10 jan. 2020.

SOARES, F. C. V. C.; RODRIGUES JÚNIOR, M. Percepção dos servidores de uma autarquia federal quanto à aderência de seu sistema de controle interno baseado na metodologia COSO.

Revista Controle, v. 17, n.1, p. 225-251, jan./jun., 2019.

https://doi.org/10.32586/rcda.v17i1.468 
SOUSA, R. G.; SOUTO, S. D. A. S.; NICOLAU, A. M. Em um mundo de incertezas: um survey sobre controle interno em uma perspectiva pública e privada. Revista Contemporânea de Contabilidade, v. 14, n. 31, p.155-176, jan./abr. 2017. http://dx.doi.org/10.5007/2175$\underline{8069.2017 \mathrm{v} 14 \mathrm{n} 31 \mathrm{p} 155}$

TANAKA, Hideomi. O controle Interno como instrumento de indução da Boa Gestão

Pública. Monografia do Curso de Especialização em Gestão Pública Municipal. UTFPR, 2012. Disponível em:

file:///C:/Users/slpsc/Documents/Artigos/UCI\%20DA\%20UERN/CT_GPM_II_2012_11.pdf. Acesso em: 16 jan. 2020. 